\title{
Winter road safety is no accident
}

\author{
Diane Kelsall MD MEd, Donald A. Redelmeier MD MSHSR
}

$\mathrm{E}$ very winter, hundreds of drivers and passengers die on slushy, snowy or icy Canadian roads - and this winter is no exception. Adverse road conditions in cold weather contribute to about $12 \%$ of traffic fatalities and injuries, with substantial local variability. ${ }^{1}$ Although traffic fatalities have decreased over time thanks to safety initiatives, ${ }^{1}$ Canadians seem to have become accustomed to a certain level of carnage on our wintry roads and highways. Canada does not fare well compared with some countries that have snowy winters, with twice as many population-adjusted traffic deaths as Sweden. ${ }^{2}$ This is unacceptable. Are the measures to keep us safe on snowy and icy roads insufficient, or are our expectations around winter unrealistic and our behaviours dangerous?

Standards for winter road maintenance vary substantially across Canada, and drivers are likely unaware of these differences. Contractors working on Ontario's major highways have eight hours to regain bare pavement after a winter storm, whereas there is no obligation to remove all ice and snow from minor highways. ${ }^{3}$ In Alberta, short sections of ice and packed snow on major highways are considered acceptable and to be expected between the wheel paths and at the centre line. ${ }^{4}$ Because the standards also differ among cities and towns, a driver's local experience is not an accurate predictor of winter conditions on unfamiliar roads.

Having standards does not mean that these standards are met. The Auditor General of Ontario published a damning report in 2015 questioning the implementation and oversight of contracting for winter highway maintenance. ${ }^{3}$ Given a built-in incentive for contractors to minimize winter safety materials, the amount of anti-icing liquid used dropped from about 3.2 million $\mathrm{L}$ to $9500 \mathrm{~L}$ per winter in one contract area. Time to bare pavement after a storm more than doubled over five years. " "[D]rivers on Ontario's highways no longer experienced the safer winter road conditions they had been accustomed to," said the auditor general. ${ }^{3}$ An increased number of traffic deaths, in turn, were blamed on snow, ice or slush. ${ }^{3}$

Canada has nearly $900000 \mathrm{~km}$ of roads - enough to go to the moon and back - and keeping them clear of ice and snow is a costly and overwhelming task. Given Canada's variable climate and topography, the amount spent on snow removal differs across the country. Montréal's snow removal budget is about $\$ 150$ million annually, whereas some entire provinces spend a fraction of that. The cost of keeping our roads clear is not limited to dollars, however. Driving a snowplow can be dangerous, with more than a dozen plow operators injured or killed on the job each year. The environmental cost of using de-icers, salt and other means of ice and snow removal may also be substantial.

Most of us are drivers, and we too are responsible for winter road safety. Counterintuitively, road fatalities and injuries are most common in the summer, likely because of overconfidence and a false sense of security. Crashes year-round often occur from factors that are under our control: excessive speed, distraction, impairment and failure to wear seat belts. ${ }^{1}$ Add in snow, ice or slush, and the risk is higher. We may not install winter tires, may over-rely on modern technology or may fail to recognize that vehicle control is substantially affected by ice and snow. ${ }^{5}$ We may be overconfident in our driving ability or try to make up time lost because of traffic delays. Some of us simply trust that roads are well maintained and make no adjustment to our manner of driving in winter.

Hundreds of deaths each winter is not a reasonable price to pay for living in a snowy country. A multifactorial approach to winter road safety is required on the part of drivers, regulators and service providers. Road maintenance standards must be examined to ensure that they meet the challenges of local weather patterns and incorporate proven technologies. ${ }^{1}$ Governments must hold service providers accountable for their performance, including conducting field audits. ${ }^{3}$ Mandatory winter tire legislation, such as that in place in the province of Quebec, should be considered where appropriate. ${ }^{5}$ Seasonal variation in speed limits (enforced by automated technology or other traffic enforcement techniques) has been effective in Europe and merits consideration. ${ }^{1}$ Education of drivers on the basics of safe winter driving is essential through public education, as well as reinforcement of standard safety advice applicable year-round. ${ }^{1}$

We also need to rethink our expectations around winter travel. There will be days each winter when it is not safe to drive to school, work or a doctor's appointment — and staying at home should be acceptable. Canadian roads will not be clear of ice and snow at all times. Sometimes it makes sense to skip the trip.

\section{References}

1. Canada's road safety strategy 2015. Ottawa: Canadian Council of Motor Transport Administrators; 2011

2. Global status on road safety report 2013: supporting a decade of action. Geneva: World Health Organization; 2013.

3. Office of the Auditor General of Ontario. Special report April 2015: winter high way maintenance. Toronto: The Queen's Printer; 2015.

4. Highway maintenance guidelines and level of service manual. Edmonton: Province of Alberta; 2000.

5. Winter tires: a review of research on effectiveness and use. Ottawa: Traffic Injury Research Foundation; 2012.

Competing interests: Diane Kelsall's niece Amanda Kelsall died in a motor vehicle accident on a snowy, icy Ontario highway on Jan. 5, 2014. See also www.cmaj.ca/site/misc/cmaj_staff.xhtml for Diane Kelsall. Donald Redelmeier practises medicine at Canada's largest trauma unit.

Affiliations: Deputy Editor (Kelsall), CMAJ; Department of Medicine (Redelmeier), University of Toronto, Sunnybrook Health Sciences Centre, Toronto, Ont.

Correspondence to: $C M A J$ editor, pubs@cmaj.ca

CMAJ 2016. DOI:10.1503/cmaj.160100 